\title{
RIBEIRO Darcy, Testemunho
}

\section{Philippe Erikson}

\section{OpenEdition \\ Journals}

Édition électronique

URL : https://journals.openedition.org/jsa/12009

DOI : 10.4000/jsa. 12009

ISSN : 1957-7842

Éditeur

Société des américanistes

\section{Édition imprimée}

Date de publication : 20 décembre 2011

Pagination : 445-447

ISSN : 0037-9174

\section{Référence électronique}

Philippe Erikson, « RIBEIRo Darcy, Testemunho », Journal de la Société des américanistes [En ligne], 97-2 I

2011, mis en ligne le 22 décembre 2011, consulté le 02 septembre 2022. URL : http://

journals.openedition.org/jsa/12009; DOI : https://doi.org/10.4000/jsa.12009

Ce document a été généré automatiquement le 2 septembre 2022

Tous droits réservés 


\title{
RIBEIRO Darcy, Testemunho
}

\author{
Philippe Erikson
}

\section{RÉFÉRENCE}

RIBEIRO Darcy, Testemunho, Editora Apicuri/Editora Universidade de Brasília, Rio de Janeiro/Brasília, 2009, 208 p., ill.

1 À l'image de la galerie de portraits qui orne son frontispice - une vingtaine de gros plans en noir et blanc représentant l'auteur à différents âges de sa vie -, cet ouvrage semiposthume de Darcy Ribeiro (1922-1997) se compose d'une collection de courts textes, quarante en tout, représentatifs des diverses facettes et des différentes étapes de la carrière de l'auteur. Les «bonnes pages» de Darcy Ribeiro, en somme, sorte de menu dégustation donnant au lecteur un aperçu global d'une œuvre dense, hétéroclite, importante, et qui aura incontestablement marqué l'américanisme tropical du $\mathrm{xx}^{\mathrm{e}}$ siècle.

2 Une première édition (aujourd'hui introuvable) de Testemunho était déjà parue à Rio de Janeiro, aux éditions Siciliano, en 1990. Cependant, cette date coïncidant avec celle de l'élection de Darcy Ribeiro au Sénat, cette version ne reçut pas toute l'attention qu'elle aurait méritée. Manquait notamment l'iconographie qui, dans la nouvelle édition, est au contraire abondante (pp.123-138). On y voit l'auteur à diverses étapes de sa fulgurante trajectoire: moustachu et peinturluré chez les Kadiwéu; chevelu mais en toge à la Sorbonne; digne, en compagnie du Maréchal Rondon, de João Goulart ou d'Oscar Niemeyer, mais hilare et/ou tonitruant lors de ses campagnes électorales; méditatif, le stylo en l'air, lorsqu'il dédicace son ouvrage à cette autre grande figure de l'ethnologie brésilienne (et par ailleurs sa première épouse), Berta Ribeiro...

3 À mi-chemin entre le testemunho et le testamento (pour reprendre une formule de l'auteur), l'ouvrage est plus qu'un simple mélange d'extraits de ses principaux écrits. De son vivant, Darcy Ribeiro avait en effet soigneusement planifié le volume et, surtout, rédigé autant de chapeaux introductifs qu'il en fallait pour restituer chaque élément dans son contexte original. On aurait donc tort de considérer ce livre comme un fourretout hétéroclite. Plutôt que simplement juxtaposés, les extraits de publications 
antérieures servent à créer l'équivalent littéraire d'un collage ou d'une mosaïque savamment construite. Les pièces anciennes sont recomposées pour aboutir à une œuvre originale, autobiographie intellectuelle où l'auteur préfère se citer que se paraphraser; œuvre produite par rétroaction, pleine d'humour et d'autodérision, et où la moitié des textes, rédigés exprès pour ce livre, assure la liaison entre les diverses parties.

Auteur prolixe, ethnologue, indigéniste, romancier, homme politique engagé, Darcy Ribeiro est surtout connu en France pour avoir tiré la sonnette d'alarme sur la situation tragique des Amérindiens de son pays, notamment dans Frontières indigènes de la civilisation, préfacé par Robert Jaulin (1979 [1971]). Ses travaux sur les Urubu-Kaapor et les Caduveo, loués en leur temps par Claude Lévi-Strauss en personne, sont également réputés. Hormis Maíra (1980 [1976]), son roman à succès traduit dans plusieurs langues rares dont le français, sans doute connaît-on moins, en revanche, l'œuvre romanesque et les essais de Ribeiro. Et moins encore, du moins en Europe, l'action politique de ce champion des gauches latino-américaines, qui fut député, ministre, exilé politique, sénateur et défenseur non seulement de la cause des minorités dans son pays, mais aussi fervent zélateur du droit des plus démunis à l'éducation populaire. Homme dont l'appui au Xavante Mario Juruna permit à ce dernier de devenir en 1982 le premier député amérindien du Brésil. Par ailleurs co-fondateur et directeur (ou recteur) d'institutions prestigieuses comme le Museo do Indio de Rio de Janeiro ou l'université de Brasilia.

C'est sans conteste une des qualités majeures de cet ouvrage que de souligner la cohérence fondamentale de ce parcours, où l'engagement politique est vécu comme la continuité logique de la démarche anthropologique, plutôt que comme son antithèse. De son choix, lors des années d'exil, de rester en Amérique latine plutôt que de se rendre en France, Ribeiro écrit : «En Europe, j'aurais poursuivi dans la voie de l'ethnographie indigène, vulgaire ethnologue de cabinet, toujours menacé de se transformer, comme tant d'autres, en notable ébaudi » (p.119) ${ }^{1}$. Voilà qui est décidément bien éloigné de l'apolitisme professé par une partie de l'intelligentsia de l'époque, notamment dans les rangs des structuralistes... Et pourtant, parmi les morceaux de bravoure figurant dans cet ouvrage, il en est un qui retiendra particulièrement l'attention d'un lectorat américaniste français : le discours de réception du doctorat honoris causa que l'université de Paris VII lui délivra en octobre 1978. Ribeiro, dans la courte présentation qu'il donne à ce texte, explique les difficultés qu'il rencontra à cette occasion:

Le défi faillit me paralyser entièrement. De fait, jamais n'avais-je eu tant de mal à écrire un discours. Deux obstacles se présentaient à moi. D'une part, je ne souhaitais pas faire l'éloge de la Sorbonne dans le rôle de supposée grand-mère des universités ou mère féconde de la culture occidentale. D'avoir planifié l'Université de Brasília en repensant l'institution depuis ses racines m'interdisait d'aussi basses flagorneries. L'autre difficulté était de contourner l'éloge de l'anthropologie française, en particulier celle de Lévi-Strauss, tellement admirée et psittacidé de toutes parts, surtout ici [au Brésil], par une certaine anthropologie déshumanisée, insensible et infidèle. (p. 16) ${ }^{2}$

6 Rétrospectivement, on voit à quel point le malentendu était profond et combien, malgré toute son érudition et tout son flair politique, Darcy Ribeiro n'avait pas saisi, ou pas voulu saisir, tous les enjeux latino-quarteniers sous-jacents à l'octroi de ce titre. Ignorait-il vraiment que ce qu'il avait autocensuré dans son discours était précisément ce que beaucoup auraient souhaité entendre? Car - à l'attention des plus jeunes rappelons que, non sans ironie, le moins que l'on puisse dire du département d'ethnologie de Jussieu de l'époque est que ses membres, Robert Jaulin en tête, ne vivaient pas plus dans le fantasme de leur continuité avec la vieille Sorbonne médiévale 
qu'ils ne vouaient une admiration sans borne au titulaire de la chaire d'anthropologie sociale du collège de France, sise un peu plus haut, rue des Écoles...

7 De telles anecdotes mises à part, Testemunho ne rajoute sans doute rien d'essentiel à l'abondante bibliographie de Darcy Ribeiro. Du moins ce livre a-t-il le mérite de présenter sous forme condensée un aperçu de l'œuvre publiée, avec quelques bonus tracks fort bienvenus. On peut recommander en sus la lecture des Carnets indiens (Ribeiro 2002 [1996]) et surtout, une visite du site web de la fondation Darcy Ribeiro [http:// www.fundar.org.br/], qui héberge une impressionnante galerie de photos et une bibliographie exhaustive de l'auteur.

\section{BIBLIOGRAPHIE}

RIBEIRO Darcy

1979 Frontières indigènes de la civilisation, Union générale d'édition, coll. « 10/18 », Paris [édition originale : 1971, Siglo XxI Editores, Mexico].

1980 Mä̈ra, roman traduit du portugais (Brésil) par Alice Raillard, Gallimard, coll. « Du monde entier », Paris [édition originale : 1976, Editora Civilização Brasileira, Rio de Janeiro].

2002 Carnets indiens. Avec les Indiens Urubus-Kaapor, Brésil, traduit du portugais par Jacques Thiériot, Plon, coll. « Terre humaine », Paris [édition originale : 1996, Companhia das Letras, São Paulo].

\section{NOTES}

1. « Na Europa teria continuado minha etnografia indígena como um mero etnólogo de gabinete e viveria sempre sob o risco de me converter num basbaque, como aconteceu com tanta gente " (traduit en français dans le texte par l'auteur, P. E.).

2. « $O$ desafio foi quase paralisante. De fato nunca tive tanta dificuldade de escrever um discurso. Dois eram os obstáculos. Por um lado, não queria fazer o elogio da Sorbonne em seu papel de suposta avó das universidades ou de mão fecunda da cultura ocidental. Tendo planejado a Universidade de Brasília, repensando a universidade desde a raiz, não podia cair em basbaquices. A outra dificuldade era não fazer o elogio da antropologia francesa, especialmente de Lévi-Strauss, tão admirado e papagaiado por toda parte, principalmente aqui, por uma antropologia desumana, insensata e infiel» (traduit en français dans le texte par l'auteur, P. E.). 


\section{AUTEURS}

\section{PHILIPPE ERIKSON}

Université Paris Ouest-Nanterre La Défense 